\title{
Ethical dilemmas in old age psychiatry
}

\author{
Catherine Oppenheimer, Gwen Adshead and Jeanette Smith
}

\begin{abstract}
Patients and their relatives somelimes make what to others appear to be unfortunate decisions. In this paper the ethical dilemmas raised by such decisions in the context of old age psychiatry are examined. The case also raises questions about financial responslbility for the care of the elderly and suggests that the health needs of patients can no longer be separated from their inancial interests.
\end{abstract}

\section{Case history (by Oppenheimer)}

Mrs Barker was 76 years old when she was first referred to the Old Age Psychiatric Service. She was a widow, living with her 52-year-old, unmarried daughter Cynthia, in a council house in a small market town. Her general practitioner requested an urgent assessment because of her anxiety, hypochondriacal fears and demanding behaviour.

Seen at home that day, she was acutely anxious, over-breathing and convinced that she was having a heart attack. Previously, she had kept house for her daughter (who worked full time as manager of a local supermarket) and was well able to manage the shopping, cooking and cleaning, but she had gradually given up these activities, and demanded more support from her daughter. Latterly she had even begun telephoning her at work to ask her to come home because she felt so ill. Cynthia was becoming worried that she would lose her job because of her frequent absences to care for her mother.

Mrs Barker was admitted to hospital with a provisional diagnosis of agitated depression. On the ward, she showed no substantial evidence of depression, but was constantly anxious, repeatedly asking for reassurance from the staff but not seeming to be helped by it. There was no evidence of cardiac or other physical disease and she had very slight memory impairment, scoring 27 out of 30 on the Mini Mental State Examination. Her activities of daily living were well preserved and she needed no help in practical matters, apart from encouragement. She was treated with lofepramine and a simple behavioural regime. After three weeks in hospital, she was discharged home with a programme of day care at the local
Social Services Day Centre, a home help and follow-up from the community psychiatric nurse.

Over the next year, the situation gradually deteriorated, she stopped attending the day centre (saying she felt too unwell) and began once again to telephone her daughter at work, seeking reassurance for her various physical symptoms. The home help was discontinued because Mrs Barker refused to allow her to do anything. preferring to rely on her daughter's help instead. Her anxiety and dependence escalated to the point where readmission to hospital became unavoidable.

After two weeks in hospital re-establishing the previous regime, her mental state returned to normal. This time, more strenuous efforts were made to prepare for her return home and to avoid another relapse. Staff worked with Mrs Barker and Cynthia, separately and together, to try and prevent Cynthia from inadvertently reinforcing her mother's maladaptive behaviour. The principles of anxiety management and the ineffectiveness of reassurance were taught to both, with only limited success. The past history of the family was explored and this helped the staff to understand Cynthia's response to her mother. Apparently her father had been a violent and abusive man and in childhood she had often been an impotent witness to his cruelty to her mother. Now, she wanted to make up to her mother as much as she could for her unhappy life. She could not accept the staff's view that her way of responding to her mother's anxiety was unhelpful in the long run, and she saw their practice of non-response to anxious questioning as harsh and unsympathetic.

Mrs Barker was discharged home with the same support as before but with the addition of day care once a week on the ward. This time it was 18 months before the situation at home broke down, as before, and she was readmitted. By now she was physically fraller and her memory loss was slightly worse, but she was still, in practice, independent in daily living skills and could have continued to live with her daughter, except that the ward staff were increasingly worried about her effect on her daughter's life. Cynthia was now using all her leisure time in 
caring for her mother and had lost her social contacts outside the home. Her frequent absences from work had been noticed by her employers and she was contemplating taking early retirement so as to devote herself to her mother entirely. At this point, Cynthia had a bad fall at home and sustained a complicated fracture of her right ankle. It was evidently impossible for her to look after her mother at home, so Mrs Barker was discharged instead, for the duration of her daughter's convalescence, to a small residential home run by a retired nurse with considerable experience of geriatric nursing. The home was able to adopt the same style of management as the hospital ward, but in a social environment much closer to normality. Over the next few months Mrs Barker became much better, as far as her mental state was concerned, than the hospital staff had ever seen her before. She was calmer, more cheerful and engaged socially with others through friendly conversation rather than through talk of her physical complaints. Nevertheless, she repeatedly asked to return to her own home and, as Cynthia became stronger, she reiterated her mother's request. Initially, Mrs Barker went to Cynthia just for weekends, but soon they asked for her to return home permanently. The psychiatric team were unhappy about this plan. Mrs Barker and Cynthia argued: First, why shouldn't Mrs Barker live at home if she wanted to? Second, why should she have to pay, out of her own savings, for residential care which she did not want and did not think she needed? Both Cynthia and her mother felt that the standard of care given in the residential home was lower than the standard that Cynthia could give.

The hospital team argued: First, if Mrs Barker returned home, her daughter would be unable to resist her demands for reassurance and her anxiety and distress would return; second, that Cynthia would have to sacrifice too much of her own life to give her mother the care she now needed. Third, although it seemed unjust that Mrs Barker had to pay for a form of care that she was being 'prescribed' on psychiatric grounds, if she returned home, she was likely once more to be admitted to hospital - a much more expensive form of care to society, although not to Mrs Barker (but this was not an argument they put to Mrs Barker and Cynthia). There would also be a financial cost to society if Cynthia took early retirement.

Mrs Barker is now at home once more. Her daughter did take early retirement. Social Services provided daily home help to relieve Cynthia of some of the burden of care, but Mrs Barker is now refusing their assistance. Cynthia is exhausted and readmission to hospital is imminent. Mrs Barker's cognitive function has further declined, and it is now questionable whether she has the capacity to make a well informed judgement about the best arrangements for herself and her daughter, taking all the relevant factors into account. Nevertheless, she clearly states that she wants to live at home, and Cynthia still maintains that her mother's wishes are the determining factors for her. Admission of her mother to hospital is acceptable to Cynthia: admission to residential care is not.

\section{Discussion}

Three issues illustrated in this case can be found, in one guise or another, throughout the practice of psychiatry in age.

(a) What people want and what they need (in the view of others) are not always the same.

The incongruence of 'wants' and 'needs' is most commonly found in old people who have a dementing illness and who do not recognise the amount of care that they have come to need. It is less usual to find (as in this case) a patient who wants more care than the professionals think necessary. Either way, setting oneself up as a better judge of the patient's needs than they are themselves is fraught with practical and ethical risks and requires one to steer a dangerous course between overprotectiveness and neglect.

(b) People's difficulties do not exist in isolation: the needs and opinions of their carers are inextricably part of their problem.

Balancing the conflicting needs and views of two (or more) people in a mutually dependent relationship is a normal part of human life. The particular colour given to this in old age comes first from the specific expectations that different people have about the needs and entitlements of older people for care from their relatives: the expectations do not necessarily fit each other. Second, from the changes in people's abilities brought about by mental or physical illness, or ageing itself. These changes create an instability in the mutual adjustment that people have arrived at, and force them repeatedly to reassess and create new adjustments. Both these factors confer extra importance on the role of the doctor. By recognising and labelling illnesses, the doctor can help the adjustment on both sides, and sometimes provides the only acceptable escape for a carer from the web of expectations, duty, guilt and compassion.

One important distinction to make when considering the role of the carer in such situations is between the carer as a 
source of information and the carer as a decision maker. The carer, especially a family member, is uniquely authoritative on information about the past, especially where the patient is no longer able to give his or her own history. Under these circumstances, the carer's view of what a patient's lifelong attitudes and preferences have been is unchallenged. Perhaps the longer a psychiatric team has been involved with a patient, however, the greater their entitlement to a view on the patient's present attitudes and preferences, a view that can stand independently of the carer's view. When it comes to making a decision, all the avallable information must be brought together, but when that has been done, the carer's judgement may have no greater standing than the judgement of others to whom the same information is available. The patient's own judgement has the highest standing, of course, but even that can be overridden under specific circumstances enshrined in law. In the case of Mrs Barker, Cynthia was probably the person best able to present her mother's stated wishes, but that did not make her better able to decide for her mother than anyone else. On the other hand, she was the best and only person able to make decisions for herself, when she decided that her own wish was to devote her life to her mother's wishes, however much the staff concerned thought her sacrifice unnecessary and fruitless.

(c) The prevailing 'mixed economy of care', where patients and their relatives have to carry financial responsibility for some types of care and not others, add new complications to decision-making governed by a patient's 'best interest': their health needs can no longer be separated from their economic interests.

One possible outcome to Mrs Barker's present situation is for the hospital team to conclude that she is no longer able to decide for herself about her needs (because of cognitive impairment) and to use the powers of guardianship under the Mental Health Act 1983 to require that she should live in a residential home: since continuing in her own home with her daughter's care is not feasible (it is an unstable situation which repeatedly breaks down) and being in hospital is not necessary. If her daughter were to object to this, and her objections were found to be unreasonably contrary to her mother's interest, legally she could be set aside as the nearest relative. The fact that her mother has always intended her savings to go to Cynthia, rather than being dissipated in her own care, and the possibility that Cynthia will lose the tenancy of the council house if her mother were permanently living elsewhere, are theoretically irrelevant to decisions about Mrs Barker's health needs. In practice, however, they are likely to play a weighty, though covert. role in everybody's thinking.

\section{Commentary (by Adshead and Smith)}

This interesting case presents considerable challenges to health care professionals. It also raises disturbing ethical issues which have already been carefully examined. We would however like to add the following comments.

Perhaps the first issue which should be addressed is the issue of competence to make decisions and about what. Is Mrs Barker competent to decide where she should live? She has not been detained under the Mental Health Act, so one might argue that she is considered competent to make at least some decisions herself. Of course people may be competent and still make decisions that appear to others to be stupid. Setting oneself up as a more competent judge of patients' needs and decisions than they are is an ethical position, which says something about the relationship between patient and the health care professional as perceived by the latter. It may also lead to risky behaviour. Second, what is the scope of the professional's duty of care? Is it to make everything better or OK, something better or $\mathrm{OK}$, or simply nothing worse? Who decides what it should be? We would argue that it should be the patient and the relatives, even if at times the outcome is not that which is welcomed by the professionals. Provided they are competent decisions, respecting the decisions of others offers them maximal respect for them as people, which is also a benefit to them. It fosters trust between the patient and professionals and makes it more likely that the patient will seek help later. Health care professionals are not responsible for the consequences of decisions made by competent adults. It may be their responsibility to support these adults in their decisions.

What 'good' is being aimed at in this case? The author appears to be aiming for prevention of hospital admission and trying to modify the relationship between a mother and her daughter.

What good will it be if Mrs Barker goes into a home and is initially happy, but is then distressed when Cynthia loses the tenancy, cannot find another one, cannot afford to purchase the house and has to move away? Even without these consequences, Mrs Barker may become 
unhappy in the home, as she would rather be with Cynthia and would also be upset if Cynthia was distressed by her mother being placed in residential care. It is therefore questionable whether this would be a 'good' outcome. Perhaps with the dependent sick, professionals need to pay as much attention to the needs of caring relatives as to the patient. Maybe if they are happy the patients will also be happy. In view of this, it is questionable whether Cynthia's judgement is of no greater standing than that of others to whom the same information is available. Furthermore, are issues such as Mrs Barker's intentions that her savings should go to Cynthia and the loss of the council tenancy, even theoretically irrelevant when deciding about Mrs Barker's health needs? If Mrs Barker is readmitted to hospital, this would be expensive to society. The cheapest option to society, but the most costly to Mrs Barker, would be for her to go into a residential home. However, should concern for society outweigh concerns for the individual patient?
Perhaps the best way of improving the status quo for Mrs Barker and Cynthia, would be to go along with their wishes and allow them to live together. However, it may be possible to negotiate additional brief periods of respite care to allow Cynthia time for herself, for example to go on holiday. Although this compromised situation may result in continuing relapses, with one admission per year, is this really so bad? Clearly, Cynthia has her own reasons for wanting to sacrifice her freedom to look after her mother, but from the history presented, her decision does appear to be a competent one and consistent with her mother's wishes.

Catherine Oppenheimer, Consultant Psychiatrist, The Warneford Hospital, Headington, Oxford OX3 7JX; Gwen Adshead, Lecturer, Department of Forensic Psychiatry, Institute of Psychiatry, De Crespigny Park, London SE5 8AF; and Jeanette Smith, Senior Registrar, Fromeside Clinic, Blackberry Hill, Bristol BS16 1ED

\title{
Activity in a district psychotherapy service
}

\author{
Richard Tillett
}

\begin{abstract}
The Royal College of Psychiatrists (1991) has recommended that all local mental health services should include speciallst psychotherapy departments. At present these are uncommon outside major teaching centres, although a considerable amount of simple psychotherapy is provided on an ad hoc basis by mental health professionals of various disciplines. This paper describes the structure, functioning and costs of a specialist department in a non-teaching district in the south west of England.
\end{abstract}

\section{Structure}

The Exeter Psychotherapy Service forms part of the mental health services provided by the Exeter and District Community Health Trust for a catchment population of approximately 300,000. About one third of the population lives in or around the city of Exeter, with the remaining two thirds in villages and market towns mainly within $\mathbf{3 0}$ to $\mathbf{4 0}$ minutes drive of Exeter. For the delivery of psychiatric care, the district is divided into six localities (four rural, two within the city), each of which has a multidisciplinary community mental health team operating from a centre within the locality. These teams provide a considerable amount of simple psychotherapy, and some teams include professionals who have had training in a particular psychotherapeutic approach (e.g. cognitive therapy, family therapy etc.).

The Psychotherapy Service is based in Exeter at Wonford House Hospital, which is on the same site as the local district general hospital, and serves as the main administrative and in-patient centre for the district's psychiatric services. The Psychotherapy Department is on the ground floor of the hospital and has its own separate entrance. There are large and small group rooms, a video suite with one-way mirror and telephone link, and five small consulting rooms. There is also a small office but at present no secretary or receptionist; secretarial and administrative support for the service is provided by the consultant's personal secretary. The depart- 